\title{
Seasonal SSH Variability of the Northern South China Sea*
}

\author{
FANG-HUA XU \\ Ministry of Education Key Laboratory for Earth System Modeling, and Center for Earth System Science, \\ Tsinghua University, and Joint Center for Global Change Studies, Beijing, China \\ LIE-YAUW OEY \\ Program in Atmospheric and Oceanic Sciences, Princeton University, Princeton, New Jersey, \\ and National Central University, Zhongli, Taiwan
}

(Manuscript received 16 September 2014, in final form 4 February 2015)

\begin{abstract}
The seasonal response of sea surface height anomaly (SSHA) to wind stress curl (WSC) in the northern South China Sea (NSCS) and the Kuroshio intrusion through the Luzon Strait is analyzed using observations and models. The dominant response to WSC is through simple Ekman pumping, while effects of $\beta$ appear as the weaker second empirical orthogonal function mode. The Luzon Strait intrusion is shown to be largely deterministic using a model forced by realistic wind in the North Pacific Ocean, and it contributes significantly to the SSH variability in the NSCS. The WSC accounts for $62 \%$, while intrusion $38 \%$ of the total forcing, but the latter alters the forced Rossby wave response. Without the intrusion, westward propagation is too fast, resulting in incorrect balance and erroneous annual SSH variability in the NSCS.
\end{abstract}

\section{Introduction}

The South China Sea (SCS) is a semienclosed sea in the northwestern Pacific. The west-east and south-north extents are approximately 1000 and $2000 \mathrm{~km}$, respectively, and the maximum depth is over $5000 \mathrm{~m}$. It exchanges waters with the western North Pacific, mainly through the Luzon Strait (Fig. 1). Early studies identify a distinct seasonal cycle of basin-scale circulation that is predominantly cyclonic in winter and anticyclonic in summer (Wyrtki 1961). This circulation is believed to be mainly driven by the monsoon wind through the generation of baroclinic Rossby waves (e.g., Liu et al. 2001; Xie et al. 2003; Gan et al. 2006). Currents on the continental shelf are affected by wind, river discharges, and flows through shallow straits, for example, the Taiwan Strait; they are not discussed in the present study. We focus on the

\footnotetext{
* Supplemental information related to this paper is available at the Journals Online website: http://dx.doi.org/10.1175/JPO-D-14-0193.s1.

Corresponding author address: Fang-Hua Xu, Center for Earth System Science, Room S921, Mengminwei Science Building, Tsinghua University, Beijing 100084, China.

E-mail: fxu@tsinghua.edu.cn
}

circulation in the open ocean of the SCS where the water depth is deeper than $500 \mathrm{~m}$.

The seasonal circulation of the northern SCS (NSCS), defined as the region north of $18^{\circ} \mathrm{N}$, has previously been found, mainly from numerical models, to depend on monsoon winds and influxes of water mass from the Luzon Strait (e.g., Metzger and Hurlburt 1996; Hu et al. 2000; Xue et al. 2004; Gan et al. 2006; Hsin et al. 2012; Xu and Oey 2014, hereinafter XO2014). The wind stress curl (WSC) is significant, and Rossby waves forced by the monsoon wind are considered to be the dominant response of the upper ocean (Liu et al. 2001; Yang and Liu 2003). However, the relative contributions from direct Ekman response and Rossby waves in the NSCS have not been discussed in previous studies; the first goal of the present study is to quantify their relative importance.

Liu et al. (2001) demonstrated that numerical experiments with the Luzon Strait closed can simulate well the response in the central and southern SCS but poorly simulate the response in the NSCS. The authors concluded that "...the Luzon Strait is important for the correct simulation of SSH variability in the most northern part of the SCS..." (Liu et al. 2001, p. 273). The Kuroshio intrudes northwestward into the SCS from the northern tip of the Philippine Islands. The Kuroshio water fraction, estimated 

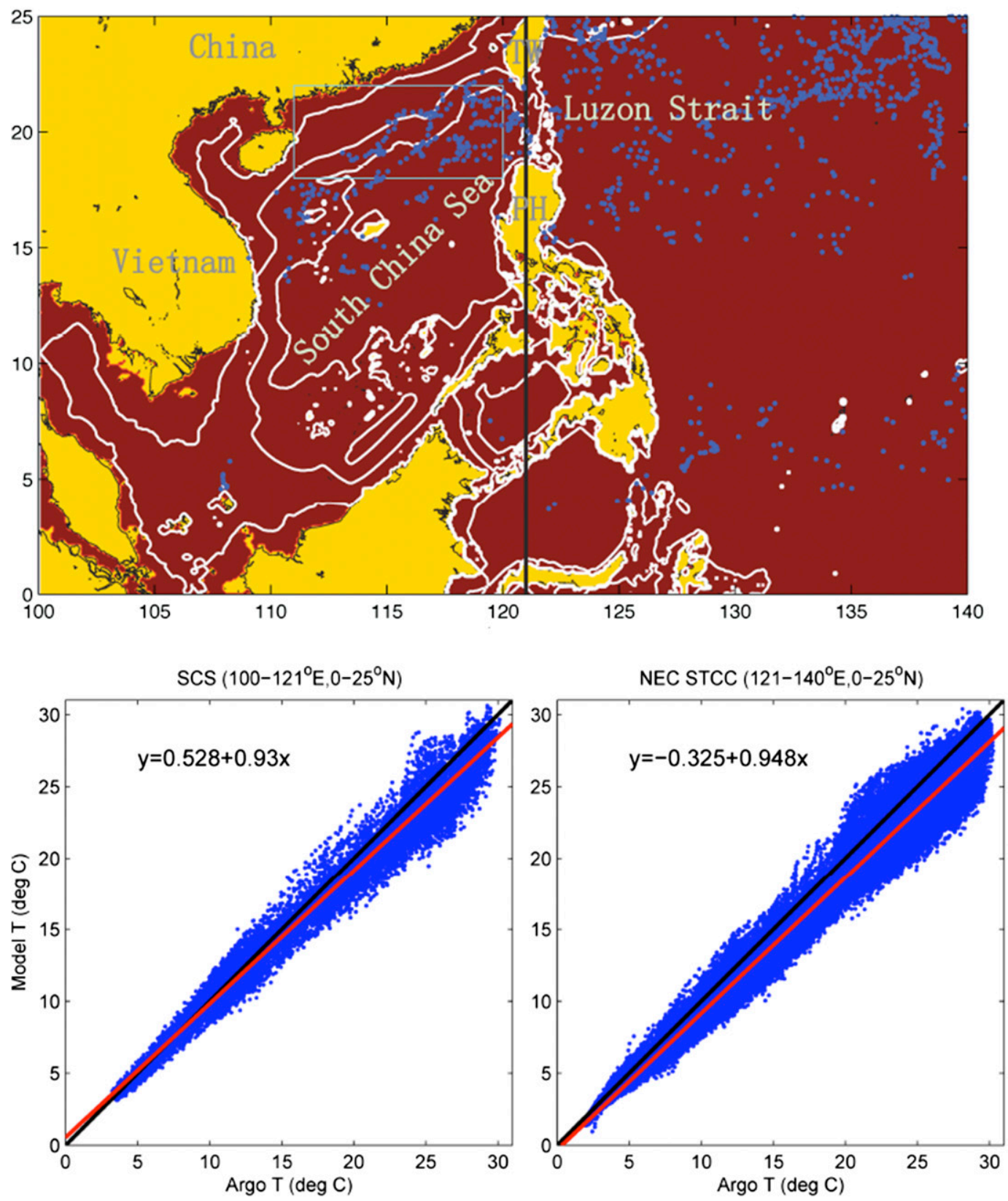

FIG. 1. (top) Map of the SCS and subtropical western North Pacific east of Luzon, including the regions of NEC and STCC. The light blue box indicates the study region in the northern SCS. White lines are 50-, 500-, and 2000-m isobaths, and the blue dots show Argo float locations. The thick vertical black line indicates $121^{\circ} \mathrm{E}$. (bottom) Comparison of model and Argo temperatures. For clarity, the comparison is plotted for $1 \mathrm{yr}$ only (2008). Black and red lines are the "perfect" and regression lines, respectively.

from potential temperature and salinity distribution in the NSCS based on an isopycnal mixing approximation, indicates that dilution by Kuroshio in the NSCS is dominant in spring and winter (Du et al. 2013). The second goal of this study is to quantify the effects of Kuroshio intrusion on SSH variability and compare them with those of the wind stress curl.

In this work, we attempt to identify the dominant driving mechanisms for the seasonal variability of SSH in the
NSCS and the associated upper-ocean circulation using an ocean model combined with analysis of wind and satellite altimetry data. The model domain includes the entire North Pacific Ocean. By conducting experiments with $\beta$ and $f$-plane approximations, and with the Luzon Strait open and closed (Table 1), we aim at deriving a better understanding of the regional dynamics in the NSCS. The manuscript is organized as follows: Section 2 describes 
TABLE 1. Three numerical experiments.

\begin{tabular}{lccc}
\hline \hline Name & $f$ plane & $\beta$ plane & Luzon Strait \\
\hline Expt.1 & No & Yes & Open \\
Expt.2 & Yes & No & Closed \\
Expt.3 & No & Yes & Closed \\
\hline
\end{tabular}

satellite data in conjunction with the simple long Rossby wave model. Section 3 describes the general circulation model for the North Pacific, numerical experiments, and model validations. Section 4 analyzes the wind effects. Section 5 describes how we extract the effects of Kuroshio intrusions on SCS circulation, which are then compared with the effects of the wind stress curl. Discussions and conclusions are given in section 6 .

\section{Altimetry data and the reduced-gravity long-wave model}

Altimetry observations provide a comprehensive picture of the seasonal change in the upper-ocean circulation. Figure 2a (left) shows a Hovmöller plot of altimetry sea surface height anomalies (SSHA) obtained from AVISO (http://www.aviso.oceanobs.com/), indicating westward propagation at a speed where $C_{R \mathrm{obs}}=0.1 \pm$ $0.01 \mathrm{~m} \mathrm{~s}^{-1}$ along $18^{\circ} \mathrm{N}$; the $C_{R \text { obs }}$ was obtained by averaging the slopes of the best-fit lines through the features. To compare this with the theoretical long Rossby wave speed $C_{R}$, we followed the method detailed in Chelton et al. (1998) to compute the first-mode baroclinic Rossby radius of deformation $R_{d}$ using the World Ocean Atlas (WOA05) climatological temperature and salinity ( $T$ and $S$ ) from NODC (Fig. 2b) (http://www.nodc.noaa. gov/OC5/WOA05/pr_woa05.html). September climatology is used in Fig. 2b as it yields the upper bound $C_{R}$, but differences with other months are small. Along $18^{\circ} \mathrm{N}$, $R_{d} \approx 55 \mathrm{~km}$, and the corresponding $C_{R}=\beta R_{d}^{2} \approx$ $0.06 \mathrm{~m} \mathrm{~s}^{-1}$, where $\beta=d f / d y$ is the variation of Coriolis parameter $f$ with latitude $y$; the mode- 1 baroclinic phase speed $C_{1}$ is calculated to be $2.5 \mathrm{~m} \mathrm{~s}^{-1}$. These values agree well with those calculated by Chelton et al. (1998). The observed propagation $C_{R \text { obs }}$ is therefore $66 \%$ faster than the Rossby wave speed. Faster observed phase speeds have been found in previous works such as the off-equatorial waves observed by the altimeter (Chelton and Schlax 1996) and forced Rossby waves south of $13^{\circ} \mathrm{S}$ in the southern tropical Indian Ocean (Masumoto and Meyers 1998).

In the NSCS, the faster observed phase speed $C_{R \text { obs }}$ may be explained using the following 1.5-layer reduced-gravity model for forced baroclinic long waves:

$$
\partial \psi / \partial t-C \partial \psi / \partial x=-w_{e}, \quad-\infty<x \leq 0, \quad t \geq 0 .
$$

Here, $\psi$ is the streamfunction of the upper layer (with mean depth $H_{o} \approx 500 \mathrm{~m}$ ) that overlies an infinitely deep, motionless lower layer; $x$ is the zonal coordinate; $x=0$ at the eastern SCS or the Luzon Strait; $t$ is time; and $w_{e}=\left(g^{\prime} H_{o} / f\right)$. The equation $\nabla \times \tau^{o} / f$ is the forcing term due to Ekman pumping, ${ }^{1}{ }^{\prime}$ is the reduced gravity $\approx 0.013 \mathrm{~m} \mathrm{~s}^{-2}$ using the above $C_{1}$ and $H_{o}$, and $\tau^{o}$ is the wind stress divided by water density. The $\psi$ is defined to have the unit of meters cubed per second and is related to the upper-layer depth $h$ by $\psi=\left(g^{\prime} H_{o} / f\right) h$. The initial and boundary conditions and $w_{e}$ are specified as

$$
\begin{aligned}
\psi(x, t=0) & =\psi_{o}(x), \quad \psi(x=0, t)=A_{E} \cos (\omega t), \\
w_{e} & =A_{\tau} \cos (\omega t),
\end{aligned}
$$

where $\omega=2 \times 10^{-7} \mathrm{~s}^{-1}\left[2 \pi(1 \mathrm{yr})^{-1}\right]$ is the annual frequency; $A_{\tau}$ is the amplitude of Ekman pumping streamfunction in units of meters cubed per second squared; and $A_{E}$ is the amplitude of $\psi$ in units of meters cubed per second at the eastern boundary. In the case of the Luzon Strait, $A_{E}$ is the amplitude of transport variation through the strait. If the eastern boundary is closed, then $A_{E}=0$. For the SCS, we take $t=0$ to be 1 January (i.e., winter) when both the WSC and inflow transport are maximum (XO2014). A solution of (1) and (2) is

$$
\begin{aligned}
\psi(x, t) & =\left(A_{\tau} / \omega\right)[\sin (\omega t)+\sin (k x-\omega t)]+A_{E} \cos (k x-\omega t) \quad \text { or } \\
& =-\left(2 A_{\tau} / \omega\right) \sin (k x / 2) \cos (k x / 2-\omega t)+A_{E} \cos (k x-\omega t),
\end{aligned}
$$

satisfying the initial condition $\psi_{o}(x)=-\left(A_{\tau} / \omega\right) \sin (k x)+$ $A_{E} \cos (k x)$, that is, the wave is considered already established in the interior region. Here, $\omega=-C_{R} k$, the long Rossby wave dispersion relation, and (3) describes westward propagation of annual Rossby waves. On the rhs of (3), the first part is wind-forced and the wave propagates westward at a velocity of $-2 C_{R}$ (White 1977), while the second part is forced by transport fluctuations through the Luzon Strait, and the resulting wave propagates westward at $-C_{R}$.

XO2014 estimated that the standard deviation of transport through the Luzon Strait is 2 Sverdrups (Sv;

\footnotetext{
${ }^{1}$ Effects of heating $(Q>0$; negative if cooling; Gill 1982) can be included by writing $\left(\nabla \times \tau^{o} / f-Q\right)$ instead of $\nabla \times \tau^{o} / f$. In the SCS, maximum cooling is in phase with maximum WSC both in December. For simplicity the two are lumped as $\nabla \times \tau^{o} / f$.
} 
(A)
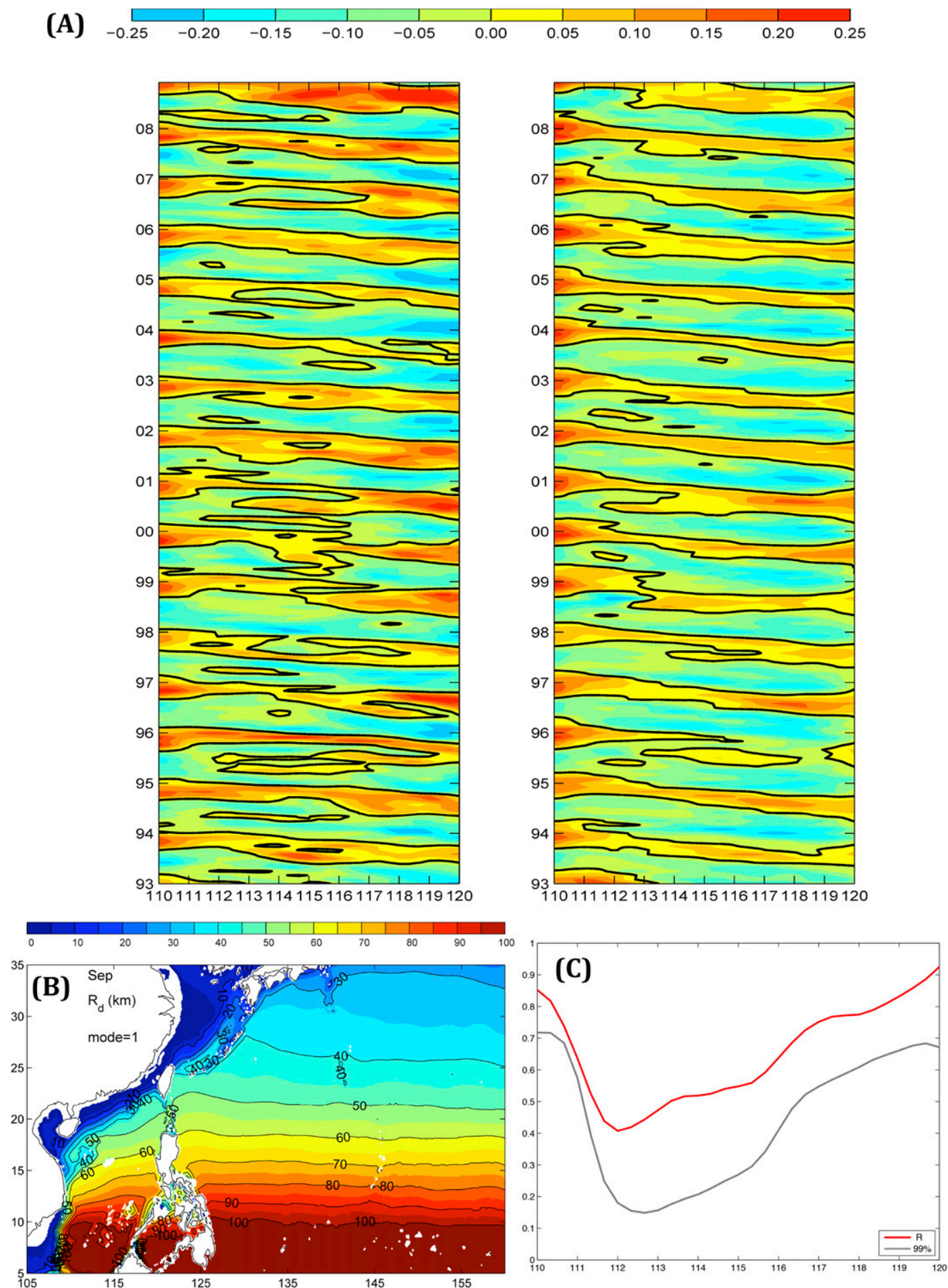

FIG. 2. (a) Hovmöller plot of SSHA (m) from (left) AVISO and (right) model (Expt.1) along $18^{\circ} \mathrm{N}$ across NSCS from $110^{\circ}$ to $120^{\circ} \mathrm{E}$; a long-term (linear least squares) trend has been removed from the SSHA. (b) First-mode baroclinic Rossby radius of deformation $R_{d}(\mathrm{~km})$ computed from the WOA05 data for September. (c) The correlation coefficient (red) between AVISO and model at $18^{\circ} \mathrm{N}$, plotted as a function of longitude $110^{\circ}-120^{\circ} \mathrm{E}$ and significant above the $99 \%$ significance level (gray). 
$\left.1 \mathrm{~Sv} \equiv 10^{6} \mathrm{~m}^{3} \mathrm{~s}^{-1}\right)$, so that in (2b), $A_{E} \approx 2 \times 10^{6} \mathrm{~m}^{3} \mathrm{~s}^{-1}$. In the SCS, the wind is northeasterly in fall and winter, southwesterly in summer, and transitional in spring (Fig. 3). The WSC shows a clear seasonal variation (see also Fig. 2 of Liu et al. 2001); west and northwest of Luzon it is positive in fall and winter and negative but weak in summer. Taking the WSC amplitude to be $10^{-10} \mathrm{~m} \mathrm{~s}^{-2}$ and $f=4.5 \times 10^{-5} \mathrm{~s}^{-1}$ at $18^{\circ} \mathrm{N}$, the amplitude of the first term in (3), $2 A_{\tau} / \omega$, is $\approx 3.2 \times 10^{6} \mathrm{~m}^{3} \mathrm{~s}^{-1}$. Therefore, the simple model suggests that in the NSCS, the WSC accounts for $3.2 /(3.2+2) \approx 62 \%$, while the Luzon Strait intrusion accounts for $2 /(3.2+$ $2) \approx 38 \%$ of the total forcing. The wind-forced term is 1.6 times stronger than the Luzon transport term, which explains why the observed westward phase speed $C_{R \text { obs }}$ (Fig. 2a) is faster than the Rossby wave speed $C_{R}$. This result may have been anticipated from the work of LaCasce (2000), which provides a detailed analysis of behaviors of the Rossby wave with different forcing.

Inferences from the simple model (1) are now used in conjunction with altimetry and wind observations to estimate which of the two physical processes dominates: the local variability $(\partial \psi / \partial t)$ term or the forced planetary wave response ( $\beta$ term, $C \partial \psi / \partial x)$. Liu et al. (2001) concluded that the $\beta$ term dominates on the basis that $C_{R}$ is large in the SCS. However, as $R_{d}$ increases from north to south (Fig. 2b), the corresponding $C_{R}$ also increases, as $R_{d}$. The balance in (1) may therefore become quite different in north than south. From the first and third terms of (1), the Ekman pumping $w_{e}$ leads $\psi$ by $\pi / 2$ or 3 months over the annual period. If $|\partial \psi / \partial t|$ is small compared to $|C \partial \psi / \partial x|$, then from the second and third terms of (1), $\psi$ is in phase with the Ekman pumping $w_{e}$. Therefore, if observational data indicate that $w_{e}$ leads $\psi$ by $\pi / 2$, then the local variability term dominates. Conversely, if the data show that $\psi$ is in phase with $w_{e}$, then the $\beta$ term dominates. To find out, empirical orthogonal function (EOF; Kutzbach 1967) analysis is carried out on monthly mean WSC from the cross-calibrated multiplatform wind (CCMP; Atlas et al. 2011) and monthly mean SSHA from AVISO (Fig. 4). Over the NSCS, mode 1 of the WSC (Fig. 4a) is seasonal and explains $95 \%$ of the total variance. The spatial pattern (SP1) shows a strong localized WSC northwest of Luzon and the principal component (PC1; Fig. 4b black line) is maximum in December and minimum from July to September. The mode-1 EOF of SSHA (Fig. $4 \mathrm{c}$ and red line of Fig. 4b) explains $60 \%$ of the total variance of SSHA. The SP1 has a localized low northwest of Luzon, which together with the corresponding PC1 contributes to a minimum (maximum) SSHA northwest of Luzon in March (October). The winter low SSHA identified by EOF1 northwest of Luzon therefore lags the maximum WSC by 3 months (cf. black and red lines in Fig. 4b). The lag correlation coefficient of the PC1s of WSC and SSHA reaches a maximum (0.92) when the WSC PC1 leads by 3 months. The mode 2 of SSHA (Fig. 4d and green line of Fig. 4b) explains $35 \%$ of the total variance, and its SP2 consists of a west-east dipole of opposite signs, with the zero-contour cutting across the middle of the NSCS from southwest to northeast. Together with the PC2, the contribution to the winter low SSHA northwest of Luzon by EOF2 is therefore in phase with the WSC (cf. black and green lines in Fig. 4b). The correlation coefficient between WSC PC1 and SSHA PC2 is maximum (0.96) at zero lag. From the above discussion of (1), mode 1 therefore represents the local variability by time-dependent Ekman pumping on an $f$ plane, and it dominates mode 2 , which represents $\beta$ effects. In the NSCS, the local variability term $|\partial \psi / \partial t|$ dominates the $\beta$ term $|C \partial \psi / \partial x|$, and the WSC drives a simple heaving and depression of isopycnals by Ekman pumping, modulated by Rossby waves. The resulting spatial patterns can be understood by examining the monthly evolution of reconstructed EOFs 1 and 2 in Fig. 4e. From late fall to early winter (November-January), the Rossby wave component EOF2 is strong, while EOF1 is weaker. The EOF2 is in phase with the strong positive WSC anomaly northwest of Luzon, and low SSHA emanates from northwestern Luzon and propagates to the southwestern coast of China. From winter to early spring (January-March), the local variability term EOF1 dominates giving rise to the strong low SSHA northwest of Luzon, while the Rossby wave from EOF2 has completely traversed the NSCS basin. From May to August, the WSC anomaly northwest of Luzon reverses sign to become positive. Westward propagation resumes but with high SSHA as EOF2 also reverses sign and becomes dominant. From September to October, the EOF1 again dominates, contributing to the strong high SSHA northwest of Luzon in early fall, completing the annual cycle.

We can verify the above inferences of local variability and Rossby wave by repeating the EOF analysis over the whole SCS from $5^{\circ}$ to $22^{\circ} \mathrm{N}$ (see supplementary material Fig.SM1). On average, the corresponding $C_{R}$ is 1.5-2 times faster and one expects the two leading EOF modes of SSHA to switch: such that PC1 is in phase with WSC, while PC2 lags WSC by 3 months, which is indeed the case (see dashed lines in Fig. 4b). For the SCS as a whole, the dominant response is therefore due to forced Rossby waves, in agreement with Liu et al. (2001). 
Winter
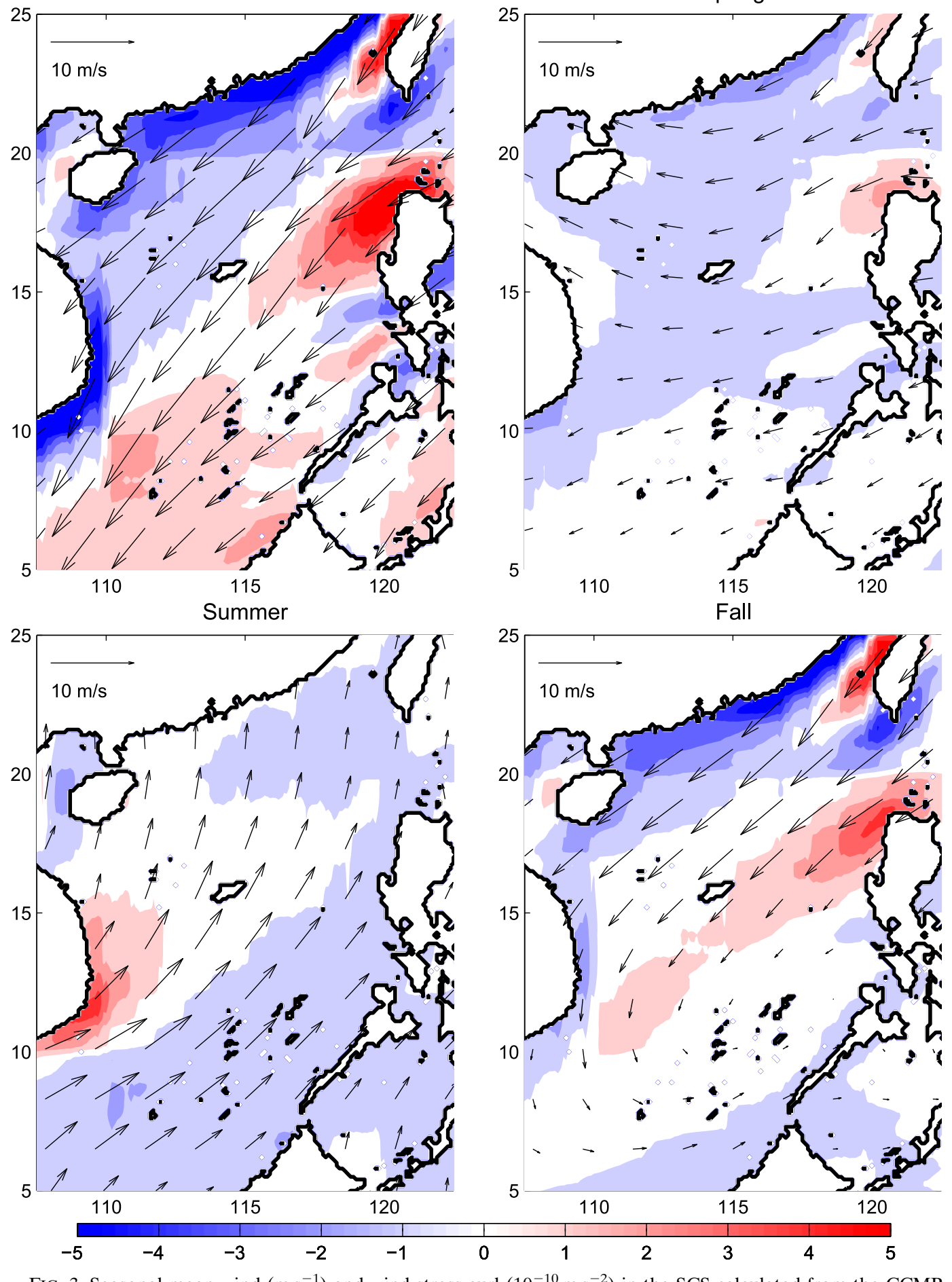

Spring

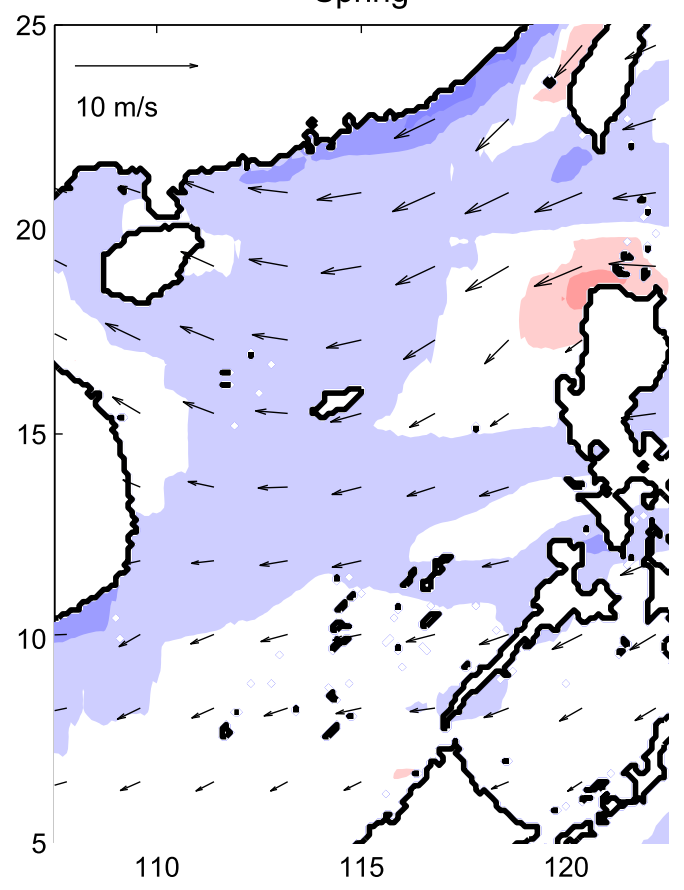

Fall

FIG. 3. Seasonal-mean wind $\left(\mathrm{m} \mathrm{s}^{-1}\right)$ and wind stress curl $\left(10^{-10} \mathrm{~m} \mathrm{~s}^{-2}\right)$ in the SCS calculated from the CCMP
data (http://podaac.jpl.nasa.gov/datasetlist?Search $=$ ccmp) from 1988 to 2009 for winter [December-February (DJF)], spring [March-May (MAM)], summer [June-August (JJA)], and fall [September-November (SON)]. 

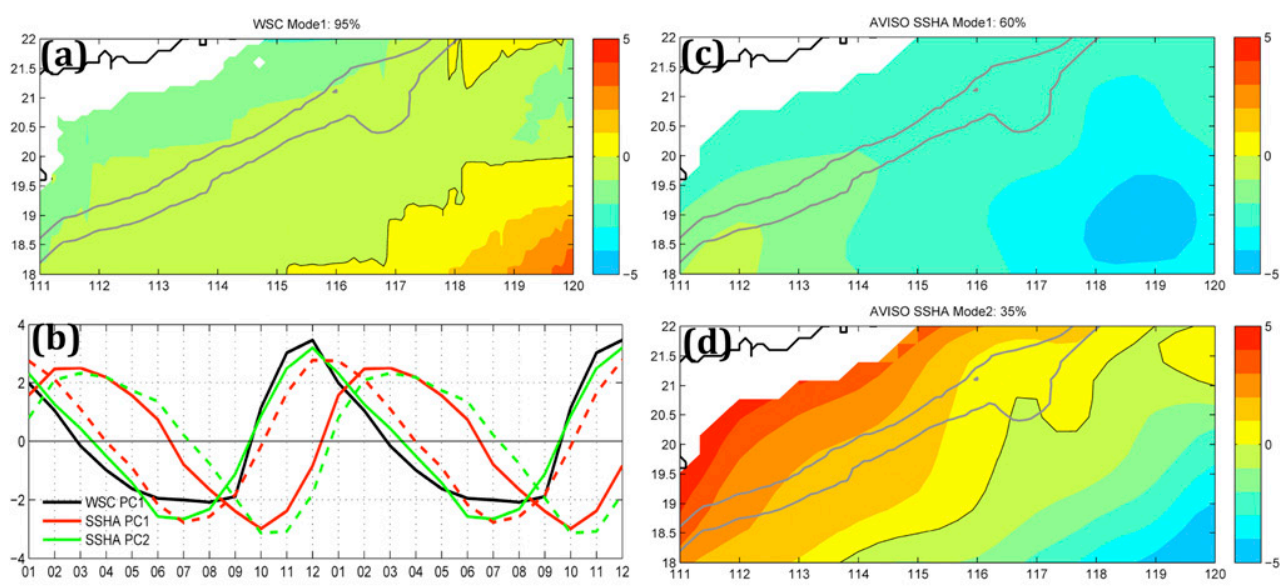

(e)
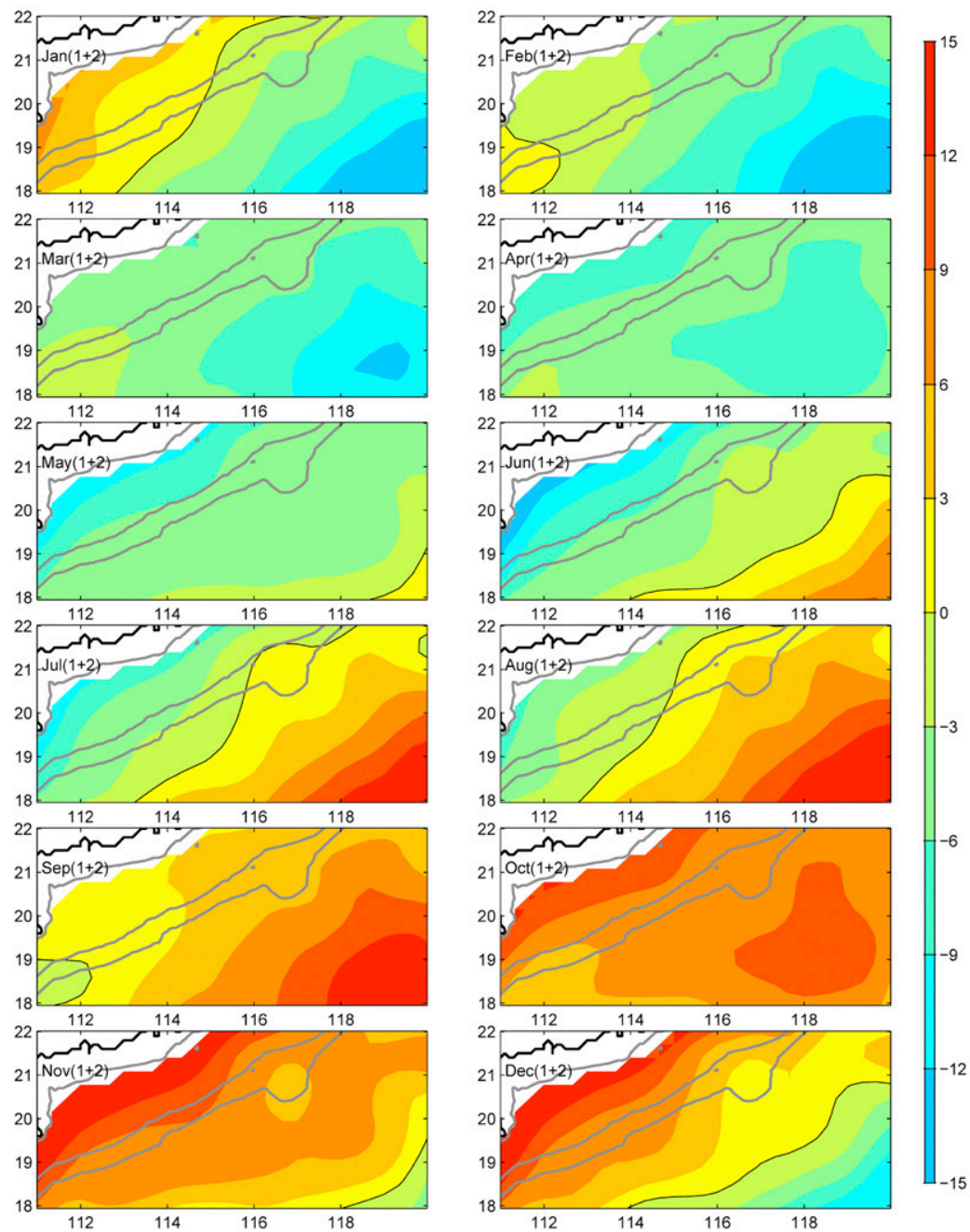

FIG. 4. (a) The EOF mode-1 spatial pattern of climatological monthly mean wind stress curl, (c) EOF mode-1 spatial pattern of climatological monthly mean AVISO SSHA, and (d) EOF mode-2 spatial pattern of AVISO SSHA. (b) Their PCs repeated over 2 yr. Red and green colors denote PC1 and PC2, respectively, while solid lines are for EOF calculated over the NSCS from $18^{\circ}$ to $22^{\circ} \mathrm{N}$, and dashed lines are for EOF calculated over SCS from $5^{\circ}$ to $22^{\circ} \mathrm{N}$. The corresponding EOF spatial patterns for the larger SCS domain are given in Fig. SM1 of the supplemental information. (e) A monthly reconstruction of EOF1 + EOF2 of SSHA 


\section{The North Pacific Ocean model}

A three-dimensional North Pacific Ocean model is used to further explore the SSH variability of the NSCS; details of the model are described in Oey et al. (2013, 2014). The model is based on the message passing interface (MPI) version of the Princeton Ocean Model (Blumberg and Mellor 1987; Jordi and Wang 2012). It is configured for the North Pacific Ocean from $15^{\circ} \mathrm{S}$ to $72^{\circ} \mathrm{N}$ and $99^{\circ} \mathrm{E}$ to $70^{\circ} \mathrm{W}$ at $0.1^{\circ} \times 0.1^{\circ}$ horizontal resolution and 41 vertical sigma levels, with realistic topography based on the ETOPO2. The sigma cells are finer, logarithmically distributed near the free surface and bottom so that the grid cell nearest the top (bottom) boundary is approximately $2 \mathrm{~m}$ below (above) the surface (bottom) in 1000-m water depth, and the corresponding grid spacing in the middle of the water column is approximately $35 \mathrm{~m}$. A fourthorder scheme is used to minimize the sigma-level pressure-gradient error (Berntsen and Oey 2010). At the sea surface, the model is forced by the CCMP wind and NCEP fluxes. Zero normal fluxes (of any kind) across solid boundaries are specified. Along the open boundaries $W O A 05 T$ and $S$ are specified within $1.5^{\circ}$-wide flow relaxation zones (Oey and Chen 1992a,b). Transports across the open boundaries along $15^{\circ} \mathrm{S}$ and $73^{\circ} \mathrm{N}$ (Bering Strait) are specified from global ocean transport (Ganachaud and Wunsch 2000) together with the Flather radiation scheme (Oey and Chen 1992a,b).

To study the influences of wind, Rossby waves, and Kuroshio intrusions on SSH variability in the NSCS, we carry out three numerical experiments (Table 1). The first experiment (control run, Expt.1) includes $\beta$ with the Luzon Strait open. The second experiment (Expt.2) is on an $f$ plane (Coriolis parameter at $18^{\circ} \mathrm{N}$ is used) with the Luzon Strait closed in order to isolate the effects of Ekman pumping only without Rossby waves. The third experiment (Expt.3) includes $\beta$, but the Luzon Strait is closed to eliminate the influences of the Kuroshio intrusions. Each experiment is initialized from a 24-yr model run forced by the CCMP wind (Oey et al. 2013) and then rerun from 1987 to 2007 to 2008 to 2012 . The first $3.5 \mathrm{yr}$ are omitted to ensure that the model has sufficient time to adjust to the (repeated) CCMP wind; for the SCS, the baroclinic adjustment time is 2-3 yr (Chang and Oey 2012; XO2014). The 18-yr model output from 1991 to 2008 is used for analyses.

\section{Model validations}

Results of the control experiment (Expt.1) have previously been validated against observations (Oey et al. 2013; Oey et al. 2014; XO2014). The modeled 18-yr mean transport through the Luzon Strait is $-5.0 \mathrm{~Sv}$, which is the intermediate between the values of the Luzon transport estimated from long-term hydrographic data: $-4.0 \mathrm{~Sv}$ by $\mathrm{Qu}(2000)$ and $-6.5 \mathrm{~Sv}$ by Chu and Li (2000). XO2014 show that the modeled transports in different seasons agree with direct measurements (their Table 3 and Fig. 9). They also show that the Luzon transport has a three-layer structure: inflow (i.e., westward) into the SCS in the upper layer from 0 to $500 \mathrm{~m}$, outflow in the middle layer from 500 to $1500 \mathrm{~m}$, and inflow again in the deep layer below $1500 \mathrm{~m}$, in good agreements with the structure inferred from direct observations (e.g., Tian et al. 2006).

To further validate the model in the SCS and east of Luzon, Fig. 1 compares modeled temperature profiles against the ARGO data in the western North Pacific. The model has a slight cold bias. Otherwise the agreements with observations are good and the slope of the regression line is close to one; it is 0.93 in the SCS. The scatter is small in the deep layers, but it becomes wider near the surface probably because of the modeled eddies and other upper-layer processes that do not match observations in a free-running model without data assimilation.

Figure 2a compares the Hovmöller plot of SSHA along $18^{\circ} \mathrm{N}$ for AVISO (left) and the model (right); their correlation as a function of longitude is shown in Fig. 2c. The model correctly simulates the seasonal intrusion through the Luzon Strait, resulting in high correlation (0.92) at the strait $\left(120^{\circ} \mathrm{E}\right)$. As explained by Yaremchuk and Qu (2004), Qu et al. (2004), and Chang and Oey (2012), the seasonally (and interannually) stronger and weaker Luzon Strait intrusions depend on the northward and southward shift of the North Equatorial Current (NEC) bifurcation latitude. The latter in turn depends on the pattern of WSC in the western North Pacific (Kim et al. 2004), in particular the WSC east of Philippines (Chang and Oey 2012). The good agreement between model and observation at the Luzon Strait is because of the high quality of the CCMP wind used by the model. The model also shows westwardpropagating features, though they are smoother than observed. As a result, the correlation decreases to a minimum (0.42) near $112^{\circ} \mathrm{E}$ before increasing again to 0.85 near the western boundary, probably because of the effects of coastal trapped waves. The model phase speed is estimated to be $0.09 \pm 0.01 \mathrm{~m} \mathrm{~s}^{-1}$ or $10 \%$ slower than observed. The slower speed is because the modeled stratification tends to be weaker in the upper layer, which results in a slower modeled first baroclinic phase speed (Fig. SM2 of the supplemental information), as evidenced by its cold bias when compared to ARGO data (model is too cold near the surface) mentioned previously.

\section{Forced local variability on $\boldsymbol{f}$ plane versus $\beta$}

To support the inferences based on AVISO that forced local variability accounts for a substantial 

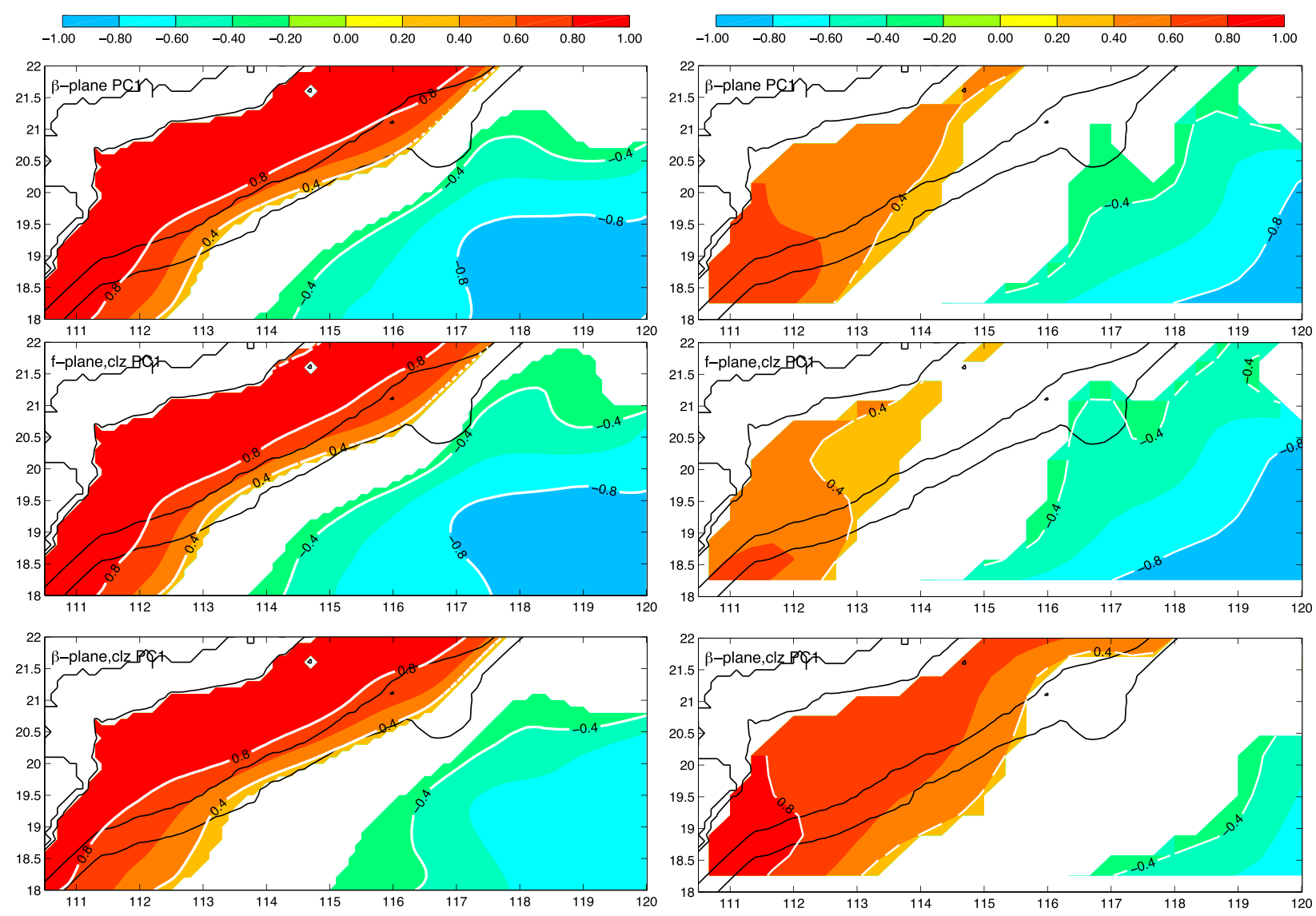

FIG. 5. The correlation maps between PC1s of (top to bottom) experiments 1, 2, and 3 and (left) Expt.1 SSH and (right) between PC1s of the same three experiments with observed (AVISO) SSH. Regions where the correlations are insignificant at the $95 \%$ significance level are shaded white.

percentage of the total variability in the NSCS, we calculate the correlation maps between EOF PC1s of the three experiments and the control run Expt.1 (Fig. 5, left). The correlation map of Expt.2 is similar to that of Expt.1. The negative correlation occurs west of the Luzon Strait where positive (negative) PC1 corresponds to lower (higher) SSH in winter (summer). In winter, the correlation becomes positive toward the northwest near the continental shelf, where SSH rises induced by negative wind stress curl and coastal setup by the northeasterly monsoon; the pattern reverses in summer. By contrast, although the correlation map for Expt. 3 shows a similar pattern, the values west of Luzon are weaker than Expt.1 and Expt.2. Similarly, we calculate the correlation maps between PC1s of the three experiments and observed SSH from AVISO (Fig. 5, right). The correlation maps of Expt.1 and Expt.2 with AVISO are similar, but that of Expt.3 shows weaker correlations west of Luzon, in good agreements with the above correlations with the SSH of Expt.1. Figure 5 therefore shows that Expt.2, which simulates only local variability by time-dependent
Ekman pumping, accounts for a large percentage of the total SSH variability in the NSCS. This result supports the inference of section 2 based on the simple, long-wave model that local variability is dominant in the NSCS. Figure 5 shows that with a closed Luzon Strait, the $\beta$-plane model Expt. 3 performs poorly (Liu et al. 2001). This latter result agrees with the simple model that the Luzon transport plays a nonnegligible role in the NSCS. When the strait is closed, westward propagation is too fast, resulting in incorrect balance and erroneous SSH variability in the NSCS (Expt.3). We note that a closed strait also increased the stratification in the NSCS, though the effects were small. The corresponding first-mode baroclinic Rossby wave speed increased by about $10 \%$ (see Fig.SM3), complementing the faster wave speed of the combined free and forced wave solution in (3).

\section{Effects of the Kuroshio intrusion}

Disturbances from the North Pacific Ocean enter the NSCS mainly through the Luzon Strait; they are called 

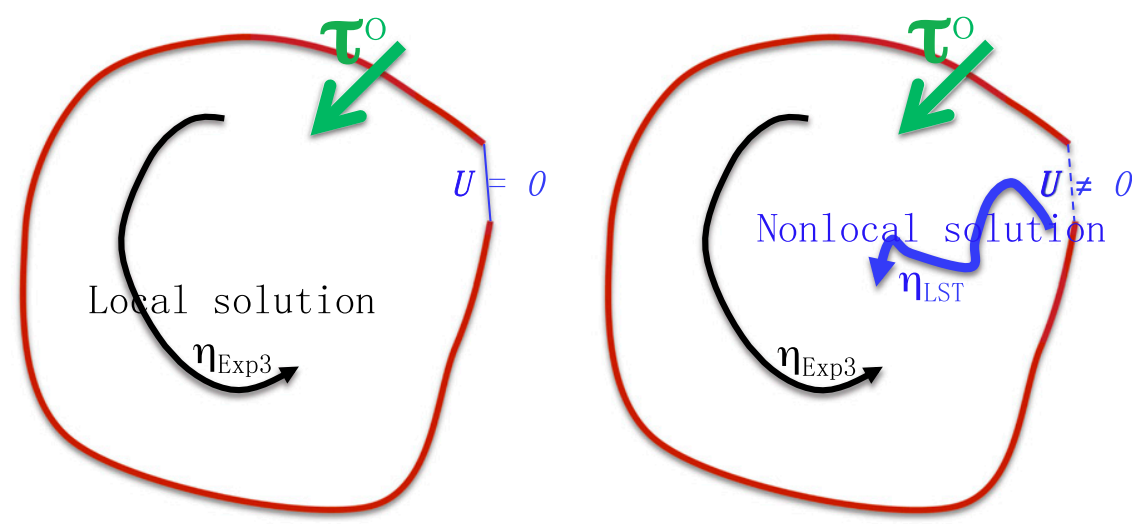

FIG. 6. A schematic plot for the SCS (left) local response to wind stress and (right) local + nonlocal response. $U=0(U \neq 0)$ denotes the Luzon Strait is closed (open); $\tau^{o}$ is the wind stress; $\eta_{\text {Exp3 }}$ is the SSHA in response to wind stress; and $\eta_{\mathrm{LST}}$ is the nonlocal solution due to Kuroshio intrusion.

Kuroshio intrusions in this work and are represented by the variability of the Luzon Strait transport (LST, negative for increased transport into the SCS). At low frequencies, the effects are transmitted into the SCS through rotational dynamics. XO2014 analyzed the LST in detail, based on the same model Expt.1 (labeled as Pac10 in that paper, their Table 3). The modeled LST shows seasonal and interannual variability (see Fig. 9 of XO2014) and compares well with available in situ measurements. On seasonal time scales, the response $\left(\eta_{\text {Exp1 }}\right.$, i.e., Expt.1) is nearly linear and may be taken as the sum of a local solution with wind only in the SCS without the Kuroshio intrusion ( $\eta_{\operatorname{Exp} 3}$, i.e., Expt.3) and a nonlocal solution with LST intrusion only but without wind $\left(\eta_{\text {LST }}\right.$ ) (Fig. 6). ${ }^{2}$ The $\eta_{\text {Exp3 }}$ is SSHA in response to wind, and $\eta_{\text {LST }}$ is SSHA due to Kuroshio intrusion; the latter is computed by subtracting Expt.3 from Expt.1:

$$
\eta_{\mathrm{LST}}=\eta_{\mathrm{Exp} 1}-\eta_{\mathrm{Exp} 3}
$$

That $\eta_{\mathrm{LST}}$ indeed represents the response due to LST is confirmed by computing its EOF. EOF1 explains $30 \%$ of the total variance and is well-separated from the next largest EOF2 that accounts for $14 \%$ of the total variance. PC1 covaries in concert with LST from 1991 to 2008 at interannual and seasonal time scales, and SP1 is largest immediately west of Luzon (Fig. 7). At the interannual time scales, the intrusions covary with an "interannual

\footnotetext{
${ }^{2}$ The wind response is mainly due to divergence/convergence caused by the wind stress curl, but $\eta_{\operatorname{Exp} 3}$ includes also a solution caused by divergence/convergence (coastal upwelling and downwelling) by wind stress at the closed Luzon Strait. The effects can be shown to be very small.
}

monsoon" index called the Philippines-Taiwan Oscillation (PTO) index (Chang and Oey 2012). Weaker intrusions occur during the negative phase of PTO during 1996, mid-1998-2001, and mid-2005-09, when PC1 is positive (Fig. 7), while stronger intrusions occur during the positive phase of PTO during 1992-95, 1997-mid1998, and 2002-mid-2005, when PC1 is negative. These interannual variations are related to the position of the NEC bifurcation, Sverdrup dynamics, and Subtropical Countercurrent (STCC) eddies, as have been discussed in detail by Chang and Oey (2012). For the present study, our main interest is the variation of intrusions at the seasonal time scale. Figure 7 shows that the intrusion is strongest (weakest) in winter (summer) when PC1 reaches a minimum (maximum) and SP1 indicates a low (high) west of the Luzon Strait.

The effects of $\eta_{\text {LST }}$ on the SCS circulation is now assessed by first examining how LST influences the response by computing its correlation with $\eta_{\operatorname{Exp} 1}$ (Fig. 8a), with AVISO SSHA $\eta_{\text {Aviso }}$ (Fig. 8b), and with $\eta_{\text {LST }}$ (Fig. 8c) and second by estimating the contribution of $\eta_{\text {LST }}$ through the correlation of its PC1 with the total response $\eta_{\operatorname{Exp} 1}$ (Fig. 8d). Figure 8a shows that LST and $\eta_{\text {Exp } 1}$ are significantly correlated $(>0.4)$ in the SCS and east of the Philippines, and the correlation exceeds 0.8 in the southern half of the Luzon Strait and west and southwest of Luzon. The correlation is weaker along approximately $14^{\circ} \mathrm{N}$ where an eastward jet tends to form during summer ( $\mathrm{Gan}$ et al. 2006). The positive correlation means that stronger LST (i.e., more negative or westward) corresponds to lower sea level in the deeper part of the SCS. The correlation is negative on the SCS shelves where sea level becomes higher with increased LST. A cyclonic circulation (anomaly) 

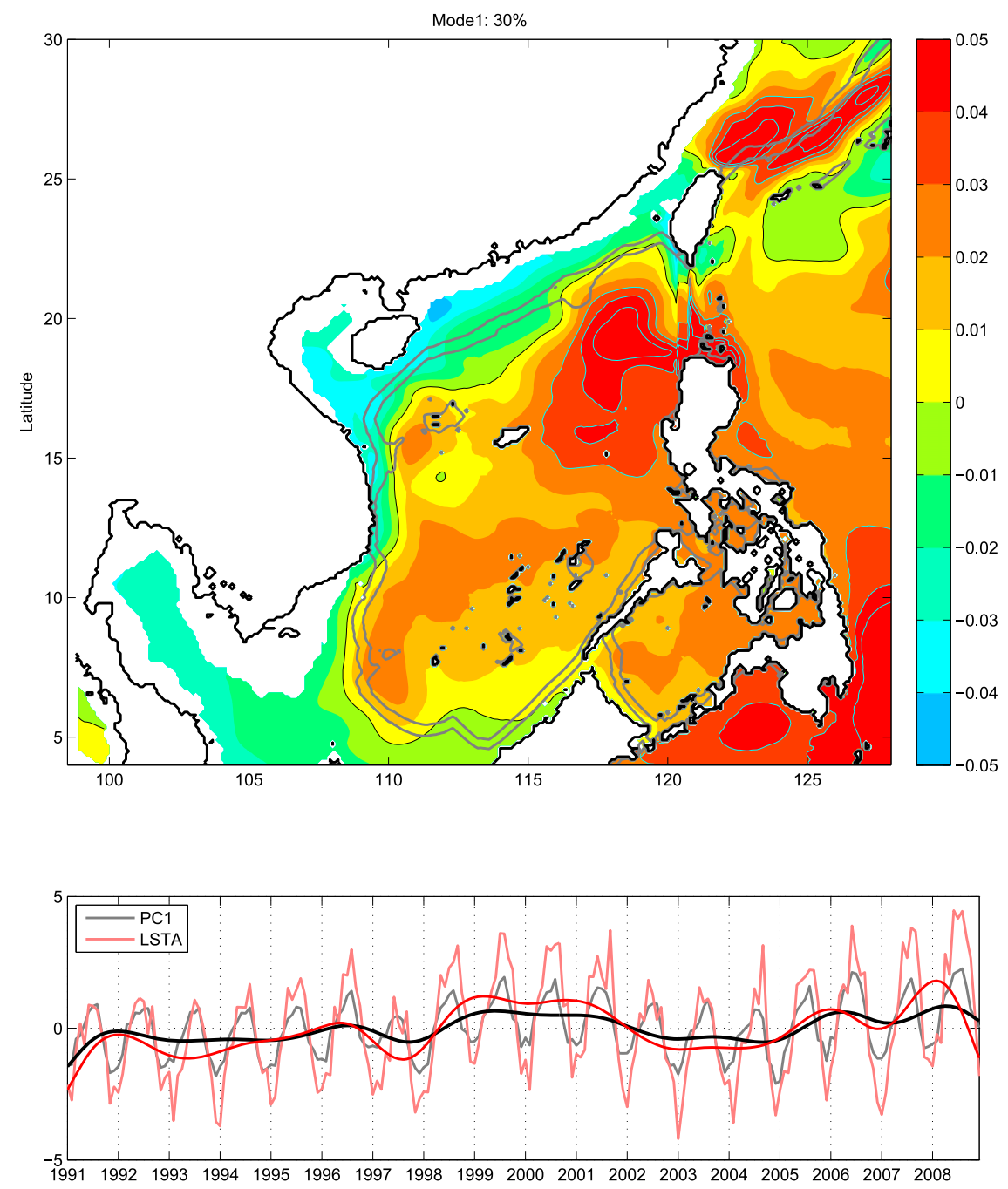

FIG. 7. (top) EOF mode-1 SP1 of $\eta_{\text {LST }}$ and (bottom) PC1 (black line) plotted together with the Luzon Strait transport anomaly (LSTA; red line) from the control experiment Expt.1. The 360 -day running-mean curves $(\times 1.5$ for visual display purpose $)$ are also plotted as thick lines.

therefore tends to be established in the SCS with increased intrusion of the North Pacific water through the Luzon Strait, as postulated by Chang and Oey (2012). The LST is maximum in December-January (XO2014) and is highly correlated with the bifurcation latitude of the NEC (NECBL; data from Qiu and Chen 2010) both at the seasonal and interannual time scales (not shown), such that northward shift of the NEC corresponds to increased LST (Chang and Oey 2012, their Table 1). These model results agree well with $\mathrm{Qu}$ and Lukas (2003), who show that the NEC bifurcation latitude is most northward in December; with Qu (2000) and Yaremchuk and Qu (2004), who show that maximum LST is in January-February; and with Yaremchuk et al. (2009), who show that the maximum LST is in December.
The above relation between LST and $\eta_{\operatorname{Exp} 1}$ is validated by correlating LST with $\eta_{\text {AVISO }}$ in Fig. 8 b, which shows good agreement with Fig. 8a. Similar to Fig. 8a, the correlation is higher in the northern SCS and west of Luzon than in the southern half of the SCS, and it is weaker along $14^{\circ} \mathrm{N}$. Over the shelves of the SCS, the correlation is negative, so that the shelves' SSH rises with increased LST. One needs to be cautious not to overinterpret the connection, however, because of potentially larger errors in altimetry data on the shelves. Such errors may explain, for example, why there is a discrepancy between Figs. $8 \mathrm{a}$ and $8 \mathrm{~b}$ on the shelf of the East China Sea where tides are strong (Lefevre et al. 2000).

The correlation between LST and $\eta_{\text {LST }}$ (Fig. 8c) confirms that the largest response of the LST is west of Luzon and the Luzon Strait. The correlation between 

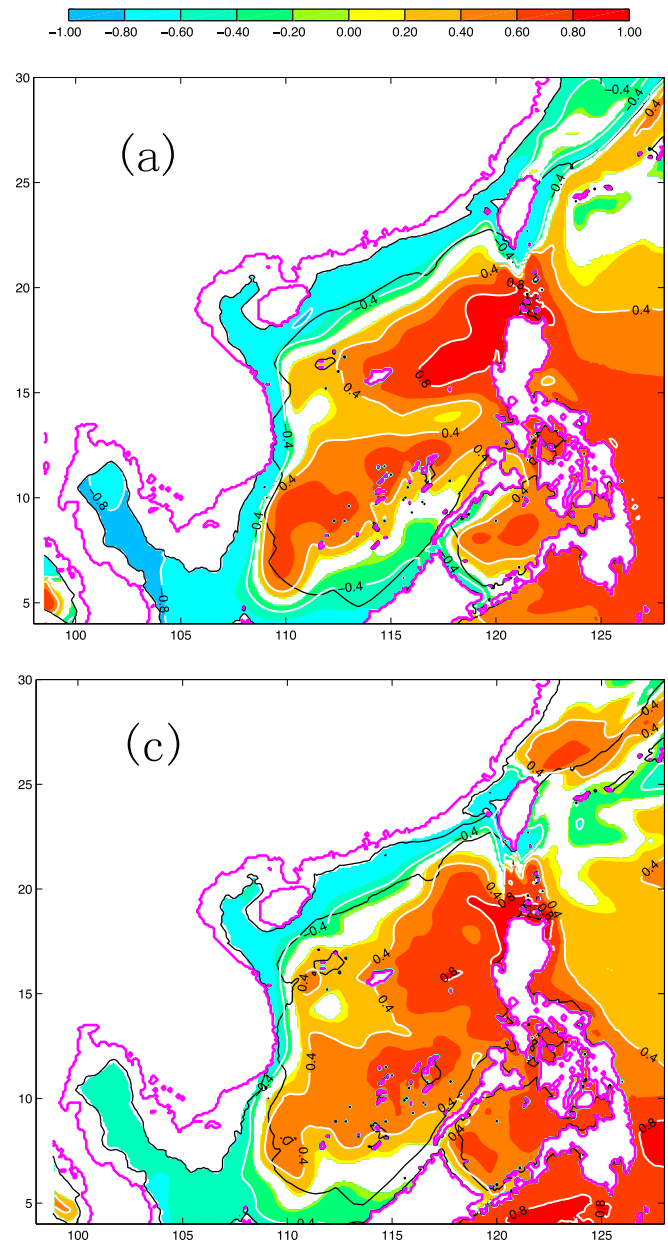
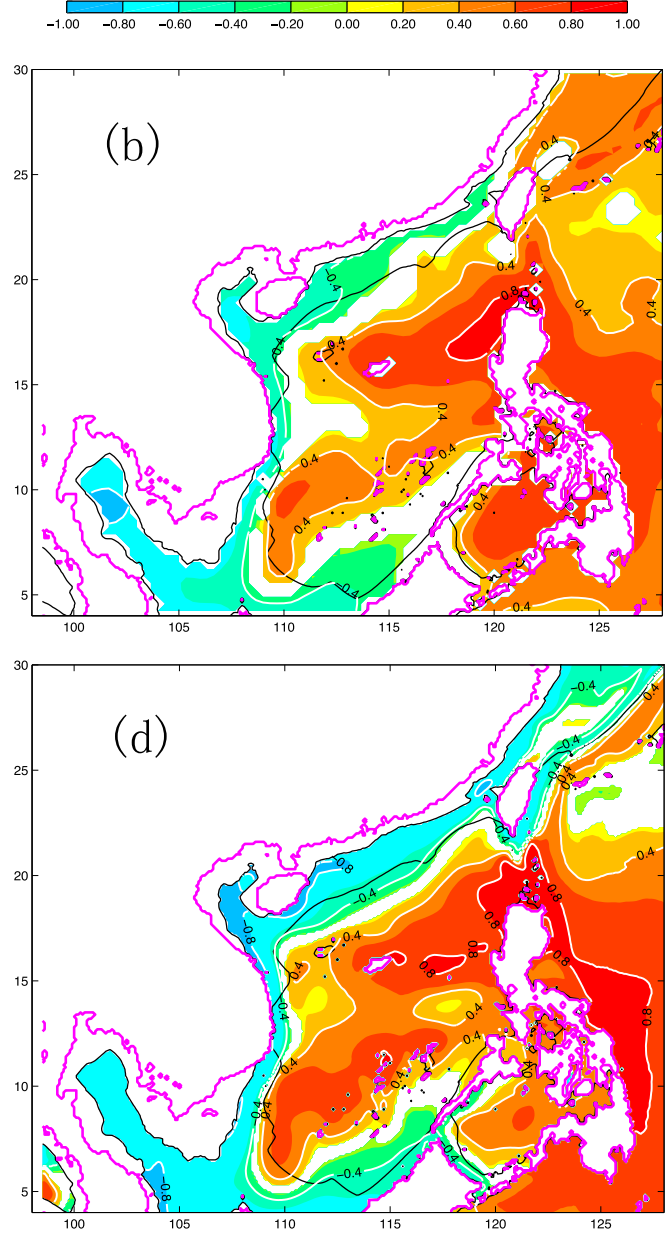

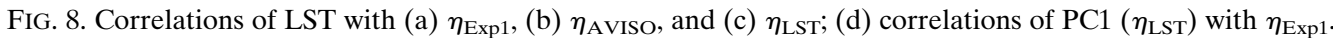
Regions where the correlations are insignificant at the $95 \%$ significance level are shaded white.

PC1 $\left(\eta_{\text {LST }}\right)$ and $\eta_{\text {Exp1 }}$ (Fig. $8 \mathrm{~d}$ ) shows that $\eta_{\text {LST }}$ accounts for a substantial portion of the total $\eta_{\text {Exp1 }}$. This is in contrast to $\eta_{\operatorname{Exp} 3}$, which we have previously shown (Figs. 4, 5) poorly represents the dominant SSH variability over the NSCS.

\section{Summary and discussion}

In this study, the seasonal response of SSHA to wind stress curl and Kuroshio intrusion in the NSCS is analyzed using models and observations. A summary of the main results follows:

1) SSHA disturbances in the NSCS propagate faster than the baroclinic Rossby wave speed $C_{R}$ (Fig. 2). However, the propagation in the NSCS is slower than in the main region of the SCS south of $18^{\circ} \mathrm{N}$ because of (i) slower $C_{R}$ in NSCS and (ii) influence of the Luzon Strait intrusion.

2) Because of the slower westward propagation, the dominant observed SSH response $(60 \%$ of total variance) in the NSCS is a simple Ekman pumping on the $f$ plane, $\partial \psi / \partial t=-w_{e}$, while effects of $\beta$, $C \partial \psi / \partial x \approx-w_{e}$, appear in the second EOF mode with half of the variance $(35 \%)$ (Fig. 4). This balance is reversed in the main portion of the SCS south of $18^{\circ} \mathrm{N}$ where the local Ekman pumping term appears then in the weaker second mode.

3) By conducting model experiments with and without $\beta$ (i.e., $f$ plane), and with the Luzon Strait closed to obtain local solutions inside the SCS only without the effects of Kuroshio intrusions through the Luzon Strait, we confirm that the local $f$-plane model can account for a larger percentage of the total variances of both model and observed SSHA's (Fig. 5, rows 1 and 2).

4) On the other hand, the local $\beta$ model of the SCS poorly explains the total solution (Fig. 5, row 3), first because effects of Kuroshio intrusion through the Luzon Strait are absent and second because then effective westward propagation is too fast leading to erroneous dynamical balance in the NSCS. 

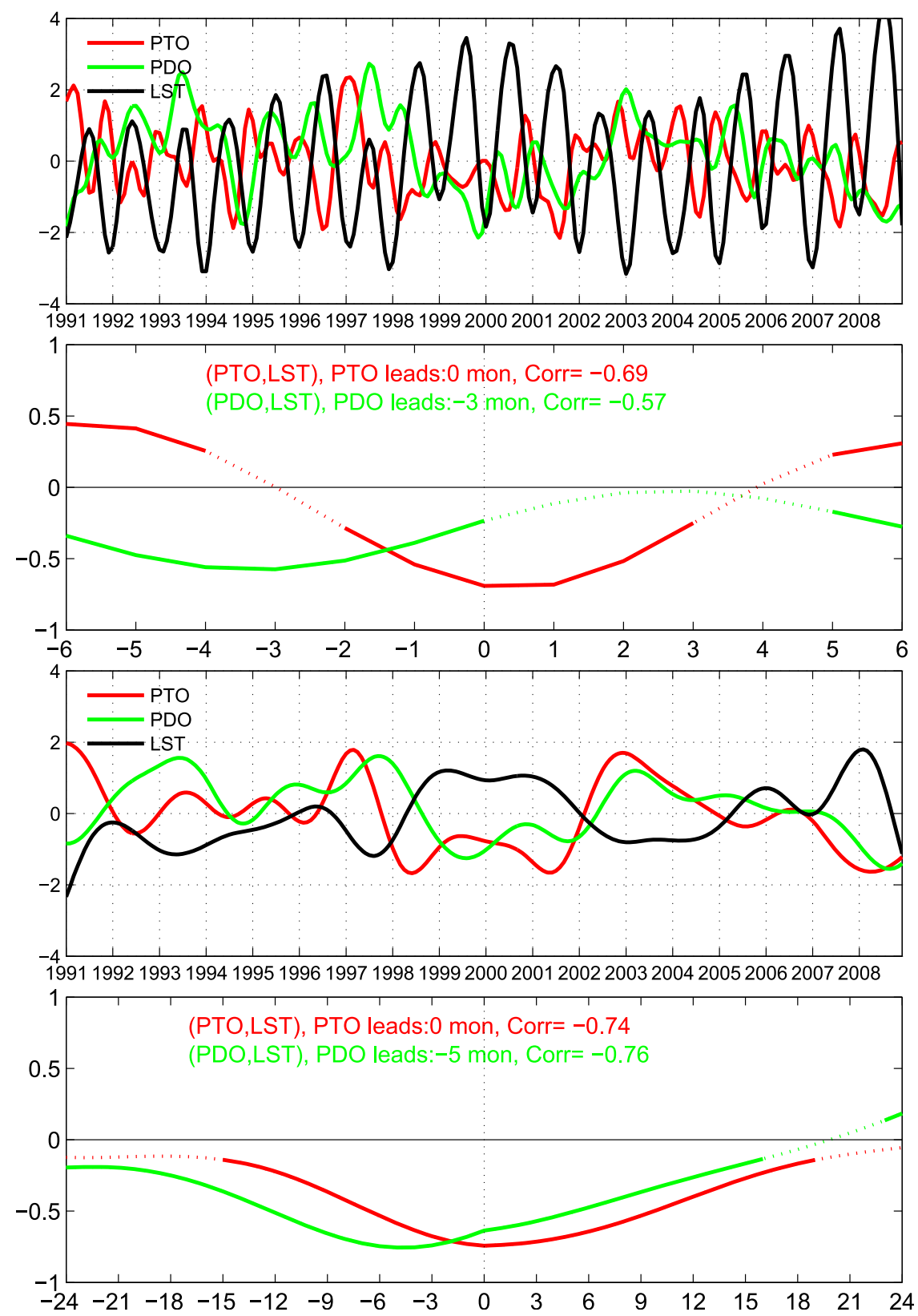

FIG. 9. Time series of PTO, PDO, and LST (from Expt.1) and their lagged correlations shown for their (top) 3-and (bottom) 12-month mean time series. In the lagged correlation plots, the $x$ axis is lag in months, and correlation values less than the $95 \%$ confidence are dotted. Positive (negative) lags mean that PDO or PTO leads (lags) LST.

5) Assuming a linear response at the seasonal (and longer) time scales, effects of Kuroshio intrusion are extracted from the model experiments; they explain well the variance previously unaccounted for by the local wind stress curl. Increased Kuroshio intrusion is shown to produce a basin-scale cyclonic circulation (Fig. 8).

Besides clarifying the effects of Ekman pumping on $f$ and $\beta$ planes, this study isolates the effects of Kuroshio intrusion and provides an explanation of why the effects cannot be neglected. Our study also shows that, given a realistic wind field in the Pacific Ocean, the seasonal intrusion through the Luzon Strait is largely deterministic with high correlation between the modeled and observed SSHA at the strait (Fig. 2c). As mentioned previously, the LST covaries with the NEC bifurcation latitude, which is most northward in December. The timing coincides with 
when the wind stress curl is maximum and, since LST excites Rossby waves (section 2), may cause some confusion (in the literature) as to the origin of forcing for the observed seasonal variability in the NSCS.

While our focus is on the seasonal variation, it is appropriate here to comment on the interannual variation of LST. As seen in Fig. 7, such a variation is significant. At interannual time scales, the LST significantly affects the SCS variability both in model and in AVISO (see Fig. SM4 in the supplemental information; also Chang and Oey 2012). What drives the interannual variability of LST? Chang and Oey (2012) show that the Pacific decadal oscillation (PDO) is significantly correlated (at the $95 \%$ confidence level; see their Table A2) with both the NEC bifurcation latitude of Qiu and Chen (2010) and the LST estimated from AVISO. However, the maximum correlations in both cases occur when PDO lags, which seems unreasonable. Tsui and Wu (2012) suggested that certain patterns of Kuroshio intrusion estimated from AVISO appear to be linked to the PDO, although no significance was reported (see their Fig. 6). Chang and Oey (2012) proposed using the PTO, a climate index based on the seesawing WSC patterns in the northwest Pacific Ocean. Figure 9 plots PTO, PDO, and LST from Expt.1 and their lagged correlations, using the 3- and 12-month running-mean time series. It confirms that both indices are significantly correlated with the LST. However, for both the 3- and 12-month mean series, PDO lags LST while PTO and LST are in phase. As PTO is closely related to the NEC bifurcation latitude (Chang and Oey 2012), these correlation analyses suggest that the LST, and hence also the SCS variability, strongly depend on the dynamics of NEC bifurcation. The details of such a connection will be the subject of a future study.

Acknowledgments. The supports for FHX from the National Basic Research Program of China (973 Program, Grant 2013CB956603) and from Tsinghua University Initiative Scientific Research Program (20141081209). LYO is grateful for the award from the Taiwan's Foundation for the Advancement of Outstanding Scholarship. Two anonymous reviewers are appreciated for their constructive comments on the manuscript.

\section{REFERENCES}

Atlas, R., R. N. Hoffman, J. Ardizzone, S. M. Leidner, J. C. Jusem, D. K. Smith, and D. Gombos, 2011: A cross-calibrated, multiplatform ocean surface wind velocity product for meteorological and oceanographic applications. Bull. Amer. Meteor. Soc., 92, 157-174, doi:10.1175/2010BAMS2946.1.

Berntsen, J., and L.-Y. Oey, 2010: Estimation of the internal pressure gradient in $\sigma$-coordinate ocean models: Comparison of second-, fourth-, and sixth-order schemes. Ocean Dyn., 60 , 317-330, doi:10.1007/s10236-009-0245-y.

Blumberg, A. F., and G. L. Mellor, 1987: A description of a threedimensional coastal ocean circulation model. ThreeDimensional Coastal Ocean Models, N. S. Heaps, Ed., Amer. Geophys. Union, 1-16.

Chang, Y. L., and L.-Y. Oey, 2012: The Philippines-Taiwan Oscillation: Monsoonlike interannual oscillation of the subtropical-tropical western North Pacific wind system and its impact on the ocean. J. Climate, 25, 1597-1618, doi:10.1175/ JCLI-D-11-00158.1.

Chelton, D. B., and M. G. Schlax, 1996: Global observations of oceanic Rossby waves. Science, 272, 234-238, doi:10.1126/ science.272.5259.234.

_, R. A. de Szoeke, M. G. Schlax, K. El Naggar, and N. Siwertz, 1998: Geographical variability of the first-baroclinic Rossby radius of deformation. J. Phys. Oceanogr., 28, 433-460, doi:10.1175/1520-0485(1998)028<0433:GVOTFB >2.0.CO;2.

Chu, P. C., and R. Li, 2000: South China Sea isopycnal-surface circulation. J. Phys. Oceanogr., 30, 2419-2438, doi:10.1175/ 1520-0485(2000)030<2419:SCSISC > 2.0.CO;2.

Du, C., and Coauthors, 2013: Impact of the Kuroshio intrusion on the nutrient inventory in the upper northern South China Sea: Insights from an isopycnal mixing model. Biogeosci. Discuss., 10, 6419-6432, doi:10.5194/bg-10-6419-2013.

Gan, J., H. Li, E. N. Curchitser, and D. B. Haidvogel, 2006: Modeling South China Sea circulation: Response to seasonal forcing regimes. J. Geophys. Res., 111, C06034, doi:10.1029/ 2005JC003298.

Ganachaud, A., and C. Wunsch, 2000: The oceanic meridional overturning circulation, mixing, bottom water formation, and heat transport. Nature, 408, 453-457, doi:10.1038/35044048.

Gill, A. E., 1982: Atmosphere-Ocean Dynamics. Academic Press, $662 \mathrm{pp}$.

Hsin, Y.-C., C.-R. Wu, and S.-Y. Chao, 2012: An updated examination of the Luzon Strait transport. J. Geophys. Res., 117, C03022, doi:10.1029/2011JC007714.

Hu, J. Y., H. Kawamura, H. Hong, and Y. Q. Qi, 2000: A review on the currents in the South China Sea: Seasonal circulation, South China Sea warm current and Kuroshio intrusion. J. Oceanogr., 56, 607-624, doi:10.1023/A:1011117531252.

Jordi, A., and D.-P. Wang, 2012: sbPOM: A parallel implementation of Princeton Ocean Model. Environ. Modell. Software, 38, 59-61, doi:10.1016/j.envsoft.2012.05.013.

Kim, Y. Y., T. Qu, T. Jensen, T. Miyama, H. Mitsudera, H.-W. Kang, and A. Ishida, 2004: Seasonal and interannual variations of the North Equatorial Current bifurcation in a highresolution OGCM. J. Geophys. Res., 109, C03040, doi:10.1029/2003JC002013.

Kutzbach, J. E., 1967: Empirical eigenvectors of sea-level pressure, surface temperature and precipitation complexes over North America. J. Appl. Meteor., 6, 791-802, doi:10.1175/ 1520-0450(1967)006<0791:EEOSLP >2.0.CO;2.

LaCasce, J. H., 2000: Baroclinic Rossby waves in a square basin. J. Phys. Oceanogr., 30, 3161-3178, doi:10.1175/ 1520-0485(2000)030<3161:BRWIAS > 2.0.CO;2.

Lefevre, F., C. Le Provost, and F. H. Lyard, 2000: How can we improve a global ocean tide model at a regional scale? A test on the Yellow Sea and the East China Sea. J. Geophys. Res., 105, 8707-8725, doi:10.1029/1999JC900281.

Liu, Z.-Y., H.-J. Yang, and Q.-Y. Liu, 2001: Regional dynamics of seasonal variability in the South China Sea. J. Phys. 
Oceanogr., 31, 272-284, doi:10.1175/1520-0485(2001)031<0272: RDOSVI $>2.0 . \mathrm{CO} ; 2$.

Masumoto, Y., and G. Meyers, 1998: Forced Rossby waves in the southern tropical Indian Ocean. J. Geophys. Res., 103, 27589 27 602, doi:10.1029/98JC02546.

Metzger, E. J., and H. E. Hurlburt, 1996: Coupled dynamics of the South China Sea, the Sulu Sea, and the Pacific Ocean. J. Geophys. Res., 101, 12 331-12 352, doi:10.1029/ 95JC03861.

Oey, L.-Y., and P. Chen, 1992a: A model simulation of circulation in the northeast Atlantic shelves and seas. J. Geophys. Res., 97, 20 087-20115, doi:10.1029/92JC01990.

—, and _ 1992b: A nested-grid ocean model: With application to the simulation of meanders and eddies in the Norwegian Coastal Current. J. Geophys. Res., 97, 20 063-20086, doi:10.1029/92JC01991.

—, Y.-L. Chang, Y.-C. Lin, M.-C. Chang, F.-H. Xu, and H.-F. Lu, 2013: ATOP-The Advanced Taiwan Ocean Prediction System based on the mpiPOM. Part 1: Model descriptions, analyses and results. Terr. Atmos. Oceanic Sci., 24, 137-158, doi:10.3319/TAO.2012.09.12.01(Oc).

,,,$----\frac{1}{-}$ S. Varlamov, and Y. Miyazawa, 2014: Cross flows in the Taiwan Strait in winter. J. Phys. Oceanogr., 44, 801-817, doi:10.1175/JPO-D-13-0128.1.

Qiu, B., and S. Chen, 2010: Interannual variability of the North Pacific Subtropical Countercurrent and its associated mesoscale eddy field. J. Phys. Oceanogr., 40, 213-225, doi:10.1175/2009JPO4285.1.

Qu, T., 2000: Upper-layer circulation in the South China Sea. J. Phys. Oceanogr., 30, 1450-1460, doi:10.1175/ 1520-0485(2000)030<1450:ULCITS > 2.0.CO;2.

— and R. Lukas, 2003: The bifurcation of the North Equatorial Current in the Pacific. J. Phys. Oceanogr., 33, 5-18, doi:10.1175/1520-0485(2003)033<0005:TBOTNE > 2.0.CO;2.

, Y. Y. Kim, M. Yaremchuk, T. Tozuka, A. Ishida, and T. Yamagata, 2004: Can Luzon Strait transport play a role in conveying the impact of ENSO to the South China Sea? J. Climate, 17, 3644-3657, doi:10.1175/1520-0442(2004)017<3644: CLSTPA $>2.0 . C O ; 2$.

Tian, J., Q. Yang, X. Liang, L. Xie, D. Hu, F. Wang, and T. Qu, 2006: Observation of Luzon Strait transport. Geophys. Res. Lett., 33, L19607, doi:10.1029/2006GL026272.

Tsui, I. F., and C. R. Wu, 2012: Variability analysis of Kuroshio intrusion through Luzon Strait using growing hierarchical selforganizing map. Ocean Dyn., 62, 1187-1194, doi:10.1007/ s10236-012-0558-0.

White, W. B., 1977: Annual forcing of baroclinic long waves in the tropical North Pacific Ocean. J. Phys. Oceanogr., 7, 50-61, doi:10.1175/1520-0485(1977)007<0050:AFOBLW>2.0.CO;2.

Wyrtki, K., 1961: Physical Oceanography of the Southeast Asian Waters. NAGA Rep., Vol. 2, Scripps Institute of Oceanography, 195 pp.

Xie, S., Q. Xie, D. Wang, and W. T. Liu, 2003: Summer upwelling in the South China Sea and its role in regional climate variations. J. Geophys. Res., 108, 3261, doi:10.1029/2003JC001867.

$\mathrm{Xu}, \mathrm{F} . \mathrm{H}$., and L.-Y. Oey, 2014: State analysis using the local ensemble transform Kalman filter (LETKF) and the three-layer circulation structure of the Luzon Strait and the South China Sea. Ocean Dyn., 64, 905-923, doi:10.1007/s10236-014-0720-y.

Xue, H., F. Chai, N. Pettigrew, D. Xu, M. Shi, and J. Xu, 2004: Kuroshio intrusion and the circulation in the South China Sea. J. Geophys. Res., 109, C02017, doi:10.1029/2002JC001724.

Yang, H., and Q. Y. Liu, 2003: Forced Rossby wave in the northern South China Sea. Deep-Sea Res. I, 50, 917-926, doi:10.1016/ S0967-0637(03)00074-8.

Yaremchuk, M., and T. Qu, 2004: Seasonal variability of the largescale currents near the coast of the Philippines. J. Phys. Oceanogr., 34, 844-855, doi:10.1175/1520-0485(2004)034<0844: SVOTLC $>2.0 . \mathrm{CO} ; 2$.

_ J. McCreary, Z. Yu, and R. Furue, 2009: The SCS throughflow retrieved from climatological data. J. Phys. Oceanogr., 39, 753-767, doi:10.1175/2008JPO3955.1. 